\title{
Introduction of a Simple Experiment for the Undergraduate Organic Chemistry Laboratory Demonstrating the Lewis Acid and Shape-Selective Properties of Zeolite Na-Y
}

\author{
Vincent Maloney* ${ }^{\star}$ and Zach Szczepanski ${ }^{\dagger}$ \\ Chemistry Department, Indiana University Purdue University Fort Wayne, Fort Wayne, Indiana 46805,United States
}

Keith Smith

School of Chemistry, Cardiff University, Cardiff CF10 3AT, United Kingdom

* Supporting Information

ABSTRACT: A simple, inexpensive, discovery-based experiment for undergraduate organic laboratories has been developed that demonstrates the Lewis acid and shape-selective properties of zeolites. Calcined zeolite $\mathrm{Na}-\mathrm{Y}$ promotes the electrophilic aromatic bromination of toluene with a significantly higher para/ortho ratio than observed under conventional conditions. The experiment can be completed in one three-hour laboratory
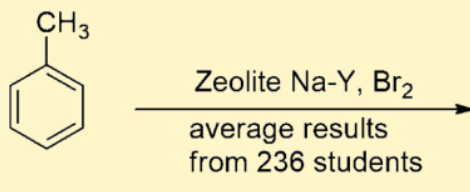

proportions

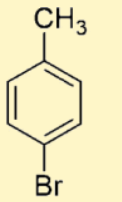

$97( \pm 3)$

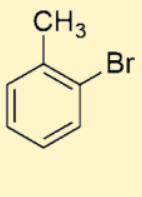

$3( \pm 3)$ period. The zeolite can be recovered

and regenerated for later reuse. A broad range of organic course topics from orientation in electrophilic aromatic substitution to photochemistry can be discussed.

KEYWORDS: Second-Year Undergraduate, Organic Chemistry, Aromatic Compounds, Electrophilic Substitution, Lewis Acids/Bases, Molecular Properties/Structure, Green Chemistry, Laboratory Instruction, Instrumental Methods

\section{INTRODUCTION}

With zeolites being employed in diverse applications, such as water softening, production of animal litter, and refining of petroleum, it is likely that most university students do not go a day without coming into contact with products and materials affected by or made with the aid of zeolites. Despite their ubiquity and the excellent experiments available in the chemical education literature, ${ }^{1}$ they still are no more prominent in undergraduate chemistry curricula than they were 20 years ago. Some of the important properties of zeolites can be easily demonstrated through their promotion of electrophilic aromatic substitution reactions.

Zeolites are aluminosilicates consisting of a network of $\mathrm{SiO}_{4}$ and $\mathrm{AlO}_{4}$ tetrahedra. ${ }^{2}$ The aluminum atoms bear a -1 formal charge, requiring the presence of countercations. As a function of these tetrahedral units and the conditions of their synthesis, zeolites contain pores and channels through which small molecules can pass and can occupy. Different zeolites have framework structures that diff er in their pore aperture sizes, cavity dimensions, and channel arrangements (intersecting or not), and within any given framework the $\mathrm{Si} / \mathrm{Al}$ ratio and countercation identity can vary. The nature of their structures and compositions can also result in zeolites containing strong Brønsted and/or Lewis acid sites. These structural features lead to three types of applications: ion exchange, adsorption and separation of compounds, and catalysis or promotion of chemical reactions. ${ }^{2}$ The zeolite used in the present study is a so-called large-pore zeolite known as zeolite Y (Figure 1) with sodium countercations. For this reason it is denoted as zeolite $\mathrm{Na}-\mathrm{Y}$.

In addition to the aforementioned properties, zeolites exhibit shape selectivity, which is of great importance in catalysis and in the promotion of reactions in general. The dimensions of the pores and channels within the zeolite can influence either the admission of reactants or the passage of products of differing sizes and shapes; the beneficial outcome is that often one product will be favored in scenarios where several would otherwise be possible. However, in some pertinent examples of electrophilic aromatic substitution reactions, the type of shape selectivity relies on a better fit of the reaction transition state for production of one isomer within the zeolite cavities, leading to the preferential formation of the corresponding product. Although important commercial examples are known, ${ }^{4}$ one dramatic case of shape selectivity suitable for undergraduate organic laboratories is the electrophilic bromination of toluene. In acetic acid without zeolites, bromination produces $67 \%$ para and $33 \%$ ortho substitution products. ${ }^{5}$ By contrast, in methylene chloride under ambient conditions in the presence of zeolite Na-Y, bromination occurs within $1 \mathrm{~h}$ and provides a 98:1 para/ortho ratio in $>99 \%$ yield. ${ }^{6}$ The zeolite provides 


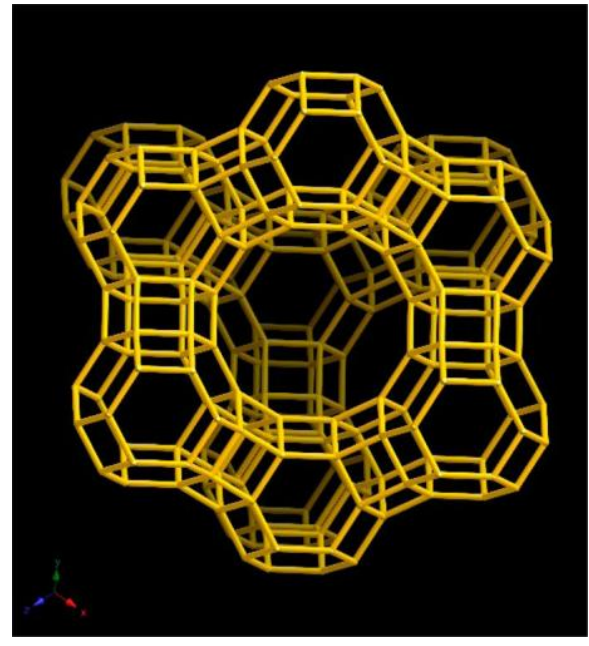

Figure 1. Structure of zeolite Y. Vertices represent the locations of Si or $\mathrm{Al}$ atoms; $\mathrm{O}$ atoms are not shown but are located at appropriate positions between vertices. The largest entry port has a ring diameter of $7.4 \AA$, and the internal cavities formed at the intersections of three mutually perpendicular channels have diameters of around $13 \AA$. Reproduced with permission from ref 3. Copyright 2017 Structure Commission of the International Zeolite Association.

Lewis acid sites for bromination and is shape-selective for the para substitution product transition state. Since $\mathrm{HBr}$ is a byproduct that deactivates the Lewis acid sites, zeolite Na$\mathrm{Y}$ promotes the reaction rather than catalyzing it.

Although excellent undergraduate experiments demonstrat-ing the properties of zeolites have been reported, ${ }^{1}$ few involve the catalysis or promotion of organic reactions. ${ }^{\text {lh-k }}$ Fewer demonstrate shape selectivity ${ }^{1 \mathrm{~h}, \mathrm{k}, 1}$ and can be conducted in one laboratory period without relatively sophisticated equipment. Although Cooke et al. ${ }^{1 \mathrm{~h}}$ reported a reaction that fulfills some of these criteria, the process described most likely occurs on the surface of the zeolite and does not demonstrate shape selectivity in the sense described earlier.

\section{EXPERIMENT}

Water strongly binds to zeolites and inhibits their potential to catalyze or promote reactions; organic residues are similarly deleterious. Thus, calcination is necessary to combust organic material, and the high temperatures required ensure that the zeolite is available in its anhydrous form. Zeolite $\mathrm{Na}-\mathrm{Y}$ can be eff ectively prepared for multiple classes of students by heating it to $550-600{ }^{\circ} \mathrm{C}$ for $24 \mathrm{~h}$ under an $\mathrm{O}_{2}$ atmosphere. Alternatively, air can be used instead of oxygen. Once the calcination is complete, the zeolite must be placed in a vacuum desiccator until needed.

The experimental procedure is rather quick and simple. Cyclohexane $(5 \mathrm{~mL})$, calcined zeolite $\mathrm{Na}-\mathrm{Y}(0.55 \mathrm{~g})$, and $10 \%(\mathrm{w} / \mathrm{w})$ toluene in cyclohexane $(0.70 \mathrm{~mL})$ are placed in a $25 \mathrm{~mL}$ round-bottom flask and stirred for $5 \mathrm{~min}$. Bromine in cyclohexane $(10 \% \mathrm{w} / \mathrm{w}, 0.43 \mathrm{~mL})$ is added, and the flask is stoppered and completely wrapped in foil. After $1 \mathrm{~h}$ of stirring in the dark, the mixture is vacuum-filtered through a fine-porosity sintered glass funnel. The filtrate is analyzed by gas chromatography-mass spectrometry (GC-MS), or simple GC can be used instead. If the equipment is readily available, the product mixture can also be analyzed by ${ }^{1} \mathrm{H}$ NMR spectros-copy.

In our implementation of this experiment, the students worked individually. They injected their own samples and acquired the data on the GC-MS instrument. Initially, methylene chloride was used as the solvent, as suggested in the original literature procedure, ${ }^{6}$ but later this was changed to the greener choice of cyclohexane with very comparable results.

\section{HAZARDS}

The procedure must be carried out in a fume hood, and safety goggles should be worn. Bromine is corrosive and toxic.

Table 1. Isomer Ratio upon Bromination of Toluene with Zeolite $\mathrm{Na}-\mathrm{Y}$<smiles>Cc1ccccc1CCC(=O)O[Na]</smiles>

1<smiles>Cc1ccc(Br)cc1</smiles>

2

$\% 2$

$97 \pm 2$

$97 \pm 3$<smiles>Cc1ccccc1Br</smiles>

$\% 3$

$3 \pm 2$

$3 \pm 3$

\section{Literature results for comparison:}

$\mathrm{CH}_{2} \mathrm{Cl}_{2}{ }^{\mathrm{d}}$ acetic acid, no $\mathrm{Na}-\mathrm{Y}^{\mathrm{e}}$

98

67
1

33

${ }^{a}$ Average results of 110 students with cyclohexane as the solvent. ${ }^{b}$ Average results of 126 students with methylene chloride as the solvent. Because of problems with the performance of the equipment at the time the students analyzed their samples in 2012 and 2014 , the samples were reanalyzed later by the supervisor, and these are the results included in the table for them. For other years, the data obtained by the students themselves are used. ${ }^{c}$ Zeolite samples used in previous years were calcined and then reused for these experiments, supplemented where necessary with fresh zeolite. ${ }^{\mathrm{d}}$ Reference $6 .{ }^{\mathrm{e}}$ Reference 5. 
Cyclohexane and toluene are flammable. Zeolite $\mathrm{Na}-\mathrm{Y}$ is an irritant. 2-Bromotoluene is an irritant and flammable. 4Bromotoluene is an irritant. All of the compounds should be handled in ways that are consistent with the corresponding MSDSs.

\section{RESULTS AND DISCUSSION}

The experiment was designed to be a discovery learning experience according to the terms used by Domin. ${ }^{7}$ In a prelab lecture and the student procedure, zeolites, their Lewis acid properties, and their ability to separate compounds were described, but shape-selective catalysis or promotion of chemical reactions was not specifically mentioned. The isomer ratio in acetic acid was provided to students, and in their reports they were asked to explain the high selectivity for the para product in their own zeolite-promoted process (Table 1). The learning objectives for the experiment and their assessment are described in the instructor notes.

The chemistry of zeolites leads to diverse opportunities for discussion, including structural features, the ability of zeolites to catalyze or promote chemical reactions in general, and more specifically, the important aspects of the electrophilic aromatic substitution under consideration in the current experiment. ${ }^{8}$ The specific reaction used here is conducted under ambient conditions, thereby minimizing energy requirements in line with one of the 12 principles of green chemistry, ${ }^{9}$ and although it is not a true catalyst for this reaction, the zeolite can be recovered and reused. The zeolite samples recovered from the students' filtrations have been calcined and reused up to four times with minimal apparent eff ect on the selectivity, reactivity, or overall yield. The very high selectivity for the para isomer leads to a reduction in waste, in line with another principle of green chemistry.

Another important aspect of the synthesis is that photobromination of the toluene methyl group is facile and benzyl bromide will be observed if the reaction mixture is not protected from light. The product mixture can be analyzed by GC. ${ }^{6}$ Alternatively, ${ }^{1} \mathrm{H}$ NMR spectroscopy can be used to study the reaction mixture, or the experiment can be pursued as a traditional synthesis if desired (details for the latter two options are discussed in greater detail in the Supporting Information). GC-MS was used here because it was pedagogically convenient to cover certain aspects of mass spectrometry. As would be expected, the mass spectra of 2-bromotoluene and 4-bromotoluene are similar, and identification was based upon retention times. Using GC-MS provides an opportunity to demonstrate the appearance of halogen isotopes in mass spectra. As indicated by GC-MS, bromocyclohexane some-times forms, and this and the formation of benzyl bromide give the opportunity for an instructor to discuss photochemistry and radical reactions to explain these observations. Furthermore, Smith et al. ${ }^{6}$ have shown that a similar procedure can be applied to other alkylbenzenes, which allows for discussion of the eff ects of substituents on the reaction.

Data from student experiments were collected from 236 students over six spring semesters (2011-2014, 2016-2017). The typical isomer ratios from student experiments are provided in Table 1. Student results within a given year were consistent and showed the same general trends within acceptable ranges of error; importantly, the results were largely unaffected by the choice of cyclohexane or methylene chloride as the solvent. By 2014, some of the zeolite samples had been used and calcined three or four times, yet the observed para to ortho ratio remained essentially the same. More than $96 \%$ of the student data clearly allowed students to observe the eff ects of shape selectivity in the zeolite-promoted reaction compared with the reaction without zeolite $\mathrm{Na}-\mathrm{Y}$.

A useful feature of this experiment is that although it is highly reproducible and therefore likely that all students will obtain good results, it remains possible to evaluate their technique and attention to detail. Poor technique becomes apparent in several ways. If the reaction mixture is not protected from light, benzyl bromide will be observed. If too little toluene or too much bromine is inadvertently used, then photobromination of the solvent may be observed upon exposure of the mixture to light after the reaction. Although it does not happen immediately, rehydration of the zeolite in the laboratory atmosphere will occur, resulting in lower percent conversion of toluene. Storage of the calcined zeolite in a vacuum desiccator for five days had no apparent eff ect on the para/ortho ratio results. In fact, samples of zeolite stored for 3 weeks gave usable results, albeit with lower percentage toluene conversion. Although experi-ments showed that the students may expose their zeolites to air for at least 30 min and possibly longer (see the Supporting Information), it is recommended that students use their zeolite samples within 15 min after removing them from the vacuum desiccator and weighing them. Although an excess of toluene is used, the amount of unreacted toluene can be a measure of the alacrity and care with which the students handled their Na-Y.

The experiment was inexpensive to perform, and cost less than \$3 per student. Less than $14 \mathrm{~mL}$ of waste should be generated per student. The zeolite was recovered and was suitable for reuse upon calcination. Since bromine is corrosive and toxic, only amounts sufficient for one laboratory class were placed in the lab at any given time.

\section{CONCLUSIONS}

The promotion of electrophilic aromatic bromination of toluene by zeolite Na-Y was remarkably easy to modify into a simple, inexpensive, discovery-based lab experiment for under-graduate laboratory courses. This experiment eff ectively demonstrated the Lewis acid and shape-selective properties of a zeolite while simultaneously allowing for the review or introduction of several seemingly unrelated lecture and laboratory topics. The experiment can be completed in one three-hour laboratory period, and most students obtain results that demonstrate important properties of zeolites.

AUTHOR INFORMATION

Corresponding Author

*E-mail: maloneyv@ipfw.edu. ORCID ๑

Vincent Maloney: 0000-0002-8289-0259 


\section{Present Address}

${ }^{\dagger}$ Z.S: Superior Essex, 1601 Wall St., Fort Wayne, IN 46802. Notes

The authors declare no competing financial interest.

\section{ACKNOWLEDGMENTS}

We thank Daryoush Tahmassebi and Eric Tippmann for assistance with the experiment in their lab classes and Indiana University Purdue University Fort Wayne and the Department of Chemistry for funding.

\section{REFERENCES}

(1) (a) Lito, P. F.; Magalhaer, A. Z.; Silva, C. M.; Fernandes, D. L. A. Permeation of Adsorbable and Non-Adsorbable Gases in Microporous Zeolite Membranes. J. Chem. Educ. 2009, 86 (8), 976-979. (b) Cooke, J.; Henderson, E. J. Experiments for the Undergraduate Laboratory That Illustrate the Size-Exclusion Properties of Zeolite Molecular Sieves. J. Chem. Educ. 2009, 86 (5), 606-609. (c) Chao, P.-Y.; Chuang, Y.-Y.; Ho, G. H.; Chuang, S.-H.; Tsai, T.-C.; Lee, C.-Y.; Tsai, S.-T.; Huang, J.-F. Study of Molecular-Shape Selectivity of Zeolites by

Gas Chromatography. J. Chem. Educ. 2008, 85 (11), 1558-1561.

(d) Pietra $\beta$, T. ${ }^{129} \mathrm{Xe}$ NMR of Zeolite NaY in the Inorganic Chemistry Laboratory. J. Chem. Educ. 2002, 79 (4), 492-493. (e) Balkus, K. J., Jr.; Ly, K. T. The Preparation and Characterization of an X-type Zeolite: An Experiment in Solid-State Chemistry. J. Chem. Educ. 1991, 68 (10), 875-877. (f) Lowe, B. M. Zeolite Molecular Sieves. Educ. Chem. 1992, 29 (1), 15-18. (g) Blatter, F.; Schumacher, E. The Preparation of Pure Zeolite NaY and Its Conversion to High-Silica Faujasite: An Experiment for Laboratory Courses in Inorganic Chemistry. J. Chem. Educ. 1990, 67 (6), 519-521. (h) Cooke, J.; Henderson, E. J.; Lightbody, O. C. Zeolite 5A Catalyzed Etherification of Diphenylme-thanol. J. Chem. Educ. 2009, 86 (8), 610-612. (i) Coker, E. N.; Davis, P. J.; Kerkstra, A.; van Bekkum, H. Experiments with Zeolites at the Secondary School Level: Experience from The Netherlands. J. Chem. Educ. 1999, 76 (10), 1417-1419. (j) Smoot, A. L.; Lindquist, D. A. Properties of Zeolite A Obtained from Powdered Laundry Detergent: An Undergraduate Chemistry Experiment. J. Chem. Educ. 1997, 74 (5), 569-570. (k) Copperthwaite, R. G.; Hutchings, G. J.; van der Riet, M. Preparation and Evaluation of a Synthetic Zeolite Catalyst: An Undergraduate Chemistry Laboratory Experiment. J. Chem. Educ. 1986, 63 (7), 632-634. (1) Bibby, D. M.; Copperthwaite, R. G.; Hutchings, G. J.; Johnston, P.; Orchard, S. W. Conversion of Methanol to Hydrocarbons Using a Zeolite Catalyst: An Undergraduate Chemistry Laboratory Experiment in Heterogeneous Catalysis. J. Chem. Educ. 1986, 63 (7), 634-637. (m) Cheung, O. Visualizing Gas Adsorption on Porous Solids: Four Simple, Effective Demonstrations. J. Chem. Educ. 2014, 91 (9), 1468-1472.

(2) Wright, P. A.; Pearce, G. M. Structural Chemistry of Zeolites. In Zeolites and Catalysis: Synthesis, Reactions, and Applications; Cejka, J., Corma, A., Zones, S., Eds.; Wiley-VCH: Weinheim, Germany, 2010; Vol. 1, pp 171-207.

(3) Baerlocher, Ch.; McCusker, L. B. Database of Zeolite Structures. http://www.iza-structure.org/databases/ (accessed February 2017).

(4) Perego, C.; Calemma, V.; Pollesel, P. Naphtha Reforming and Upgrading of Diesel Fractions. In Zeolites and Catalysis: Synthesis,

Reactions, and Applications; Cejka, J., Corma, A., Zones, S., Eds.; Wiley-VCH: Weinheim, Germany, 2010; Vol. 2, pp 585-621.

(5) Anslyn, E. V.; Dougherty, D. A. Modern Physical Organic Chemistry; University Science Books: Sausalito, CA, 2006; p 610.

(6) Smith, K.; El-Hiti, G. A.; Hammond, M. E. W.; Bahzad, D.; Li, Z.; Siquet, C. Highly Efficient and Selective Electrophilic and Free Radical Catalytic Bromination Reactions of Simple Aromatic Compounds in the Presence of Reusable Zeolites. J. Chem. Soc., Perkin Trans. 1 2000, 2745-2752.

(7) Domin, D. S. A Review of Laboratory Instruction Styles. J. Chem. Educ. 1999, 76 (4), 543-547.
(8) (a) Smith, K.; El-Hiti, G. A. Use of Zeolites for Greener and More Para-Selective Electrophilic Aromatic Substitution Reactions. Green Chem. 2011, 13 (7), 1579-1608. (b) Smith, K.; Bahzad, D. Highly Efficient Para-Selective Bromination of Simple Aromatic Substrates by Means of Bromine and a Reusable Zeolite. Chem. Commun. 1996, No. 4, 467-468.

(9) Anastas, P. T.; Warner, J. C. Green Chemistry: Theory and Practice; Oxford University Press: New York, 1998. 